\title{
Cerebellar Ataxia Associated with Glutamic acid Decarboxylase Autoantibody (Anti GAD)
}

Ana Catarina Dionísio*, Ricardo Gomes, Isabel de La Cal Caballero, Rita Elvas, José Proença, Leopoldina Vicente

Internal Medicine Department, Centro Hospitalar Universitário Cova da Beira Hospital Pêro da Covilhã, Quinta do Alvito, 6200-251, Covilhã

DOI: $10.36347 /$ sjmcr.2020.v08i01.017

| Received: 10.01.2020 | Accepted: 17.01.2020 | Published: 18.01.2020

*Corresponding author: Ana Catarina Dionísio

Abstract

Cerebellar ataxia implies changes in motor coordination and balance. An etiological study is difficult given the countless differential diagnoses. Autoimmune causes, namely due to anti-GAD antibodies, represent only around $2 \%$ of progressive cerebellar ataxia in adults [1]. The case presented is of a woman with a history of epilepsy and alopecia universalis that began to show a condition of cerebellar ataxia whose study revealed an autoimmune ataxia with positive Anti-GAD 65 antibodies. Therapeutics with intravenous immunoglobulin enabled partial improvement of the symptoms.

Keywords: Cerebellar ataxia; Anti-GAD; immunosuppressant's.

Copyright @ 2020: This is an open-access article distributed under the terms of the Creative Commons Attribution license which permits unrestricted use, distribution, and reproduction in any medium for non-commercial use (NonCommercial, or CC-BY-NC) provided the original author and source are credited.

\section{INTRODUCTION}

Cerebellar ataxia is characterized by changes in motor coordination and balance. The etiology of cerebellar ataxia includes toxic, immune-mediated factors, vitamin deficiencies, infections, and genetic and degenerative diseases [2].

The differential diagnosis is broad, which many times delays beginning treatment. Anti-GAD autoimmune cerebellar ataxia partially responds to immunosuppressant therapy [3].

It is more common in women in their sixties and, in $72 \%$ to $92 \%$ of the cases, it is associated to other auto-immune entities, such as diabetes mellitus, thyroiditis, pernicious anaemia, stiff person syndrome, epilepsy, alopecia or paraneoplastic syndromes[3-5].

Various authors mention that there is a relation between therapeutic success and the timely beginning of treatment, so prompt investigation is important $[6,7]$.

\section{Case Report}

The case presented is of a 51-year-old, previously independent, woman that started to progressively suffer from imbalance and dizziness, as well as from a decrease in strength in her right upper and lower limbs, and dysarthria. She also mentioned having vertigo and blurred vision.
She reported various episodes of falling at home and her symptoms progressively worsened even though she was being medicated with anti-dizziness medication. Her clinical condition led to great difficulty in walking, with the dizziness being incapacitating and leading to the need to lie down for most part of the day.

In her medical history, the patient presented epilepsy controlled with anticonvulsants and universal alopecia that did not respond to the cycles of corticotherapy to which she had already been submitted.

The patient began to be investigated within the context of outpatient consults and was later admitted to the hospital, nearly 6 months after the beginning of the condition, to investigate right hemiataxia and hypoesthesia.

When first admitted, the patient presented dysmetria on the right finger-nose and heel-knee test, dysarthria, decreased strength in the right upper limb, mostly proximal (4/5), and similar in the right lower limb. She also mentioned hypoesthesia in the right hemibody.

She was subject to a broader analytical and imaging exam and to a lumbar puncture during the diagnostic investigation. 
The brain imaging scans ruled out tumours or vascular causes. The hypothesis of paraneoplastic syndrome was also ruled out.

The laboratory study ascertained the presence of anti-GAD 65 antibodies (subsequently confirmed), which were the probable cause for cerebellar dysfunction.

While admitted, she also underwent immunosuppressant treatment with intravenous human immunoglobulin, which partially improved her dizziness and dysarthria. There was also some improvement in her walking capacity, and she began to walk with the help of a walker.

Upon returning home, she was able to resume some activities of everyday life, such as washing the dishes, although with some difficulty due to the decrease in dexterity in her right hand. She is able to walk with a walker, although she still has episodes of dizziness that cause her some imbalance.

The patient continues to be followed by the internal medicine and neurology departments in outpatient consults and has been submitted to other cycles of intravenous immunoglobulin, with a small improvement in her neurological condition. This has led to further improvements in the patient's clinical condition, which although small, have greatly improved her quality of life.

\section{DISCUSSION}

Glutamic acid decarboxylase (GAD) catalyzes the conversion of glutamate in y-aminobutyric acid (GABA) in the central nervous system and in the pancreatic beta cells [8].

The antibodies directed to GAD 65 have an uncertain pathological significance, arising, however, in stiff person syndrome, cerebellar ataxia, epilepsy and in diabetes mellitus, among other pathologies [9].

The patient mentioned in the reported case had presented alopecia universalis and epilepsy for several years and began to develop a condition of progressive and incapacitating cerebellar ataxia.

\section{Conclusion}

It is crucial to broaden the etiological study, ruling out potential paraneoplastic causes, as well as infectious causes. Many times, when there is strong suspicion of an auto-immune cause, it is acceptable to perform a therapeutic test with immunosuppressant therapy even prior to the definitive results of the autoimmune study, since timely treatment can influence the recovery of deficits [10].

\section{REFERENCES}

1. Hadjivassiliou M. Immune-mediated acquired ataxias. In Handbook of clinical neurology). Elsevier. 2012, 1(103):189-199

2. Barsottini OG, Albuquerque MV, Braga Neto P, Pedroso JL. Adult onset sporadic ataxias: a diagnostic challenge. Arquivos de neuropsiquiatria. 2014 Mar;72(3):232-40.

3. Mitoma H, Adhikari K, Aeschlimann D, Chattopadhyay P, Hadjivassiliou M, Hampe CS, Honnorat J, Joubert B, Kakei S, Lee J, Manto M. Consensus paper: neuroimmune mechanisms of cerebellar ataxias. The Cerebellum. 2016 Apr 1;15(2):213-32.

4. Fernandes M, Munhoz RP, Carrilho PE, Arruda WO, Lorenzoni PJ, Scola RH, Werneck LC, Teive HA. Neurological disorders associated with glutamic acid decarboxylase antibodies: a Brazilian series. Arquivos de neuro-psiquiatria. 2012 Sep;70(9):657-61.

5. Hadjivassiliou M. Primary Autoimmune Cerebellar Ataxia (PACA). Advances in Clinical Neuroscience and Rehabilitation, January/February. 2010, 9(6)

6. Jones AL, Flanagan EP, Pittock SJ, Mandrekar JN, Eggers SD, Ahlskog JE, McKeon A. Responses to and outcomes of treatment of autoimmune cerebellar ataxia in adults. JAMA neurology. 2015 Nov 1;72(11):1304-12.

7. Ariño H, Gresa-Arribas N, Blanco Y, MartínezHernández E, Sabater L, Petit-Pedrol M, Rouco I, Bataller L, Dalmau JO, Saiz A, Graus F. Cerebellar ataxia and glutamic acid decarboxylase antibodies: immunologic profile and long-term effect of immunotherapy. JAMA neurology. 2014 Aug 1;71(8):1009-16.

8. Honnorat J, Saiz A, Giometto B, Vincent A, Brieva L, de Andres C, Maestre J, Fabien N, Vighetto A, Casamitjana R, Thivolet C. Cerebellar ataxia with anti-glutamic acid decarboxylase antibodies: study of 14 patients. Archives of neurology. $2001 \mathrm{Feb}$ $1 ; 58(2): 225-30$

9. Georgieva Z, Parton M. Cerebellar ataxia and epilepsy with anti-GAD antibodies: treatment with IVIG and plasmapheresis. BMJ case reports. 2014 Jan 13;2014:bcr2013202314.

10. Quintas S, Ruiz RL, Zapata-Wainberg G, Vivancos J. Rapidly progressing cerebellar ataxia associated with anti-GAD antibodies. Neurologia (Barcelona, Spain). 2018 May;33(4):273. 